\title{
Capturing community of practice knowledge for student learning
}

\author{
Craig Zimitat* \\ University of Tasmania, Australia
}

Case studies are an important vehicle for student learning in problem-based learning curricula and higher education. WebCaseStudy.com was designed to support student learning through case studies in a simulated community of practice. This paper reports on the process of capturing community of practice knowledge for case studies to support student learning.

\section{Introduction}

All workplaces are full of stories that relate to learning and solving problems. Whilst some of these stories may be about simple matters, the ones of interest in higher education are formalised as case studies of difficult problems encountered in day-to-day professional work. They may emerge within a community of practice $(\mathrm{CoP})$ and contain a number of sub-problems without clear boundaries or constraints and multiple solutions (Jonassen, 1997). For novice learners, such as undergraduates and new graduates, these case studies are important because they illustrate how experts draw upon past experiences when making decisions in situations characterised by uncertainty, may substitute for direct experience in the workplace, and smooth the transition to employment (Ericsson \& Smith, 1991; Williams, 1992; Eraut, 2000).

\section{Learning in a CoP}

In The Social Life of Information, Brown and Duguid (2000) documented the experiences of Xerox photocopy repairmen. Photocopiers fail in many different ways because of subtle interactions between the machine, its environment and the pattern of machine usage. Repairmen had access to manuals to give guidance, however, they were of little help with difficult problems. Xerox found that the repairmen were engineering opportunities to get together informally and share experiences to solve tough problems. Less-experienced repairmen learned from more-experienced

\footnotetext{
* Centre for Advancement of Learning and Teaching, University of Tasmania, Locked Bag 1341, Launceston, Tasmania, Australia, 7250. Email: craig.zimitat@utas.edu.au
} 
colleagues. This support network for troubleshooting developed a shared body of knowledge based on stories and anecdote that circulated within their CoP. This situation is much like apprenticeship learning which is also 'supported by conversations and stories about problematic and especially difficult cases' (Lave \& Wenger, 1991, p. 108). Lave and Wenger termed this support network as a CoP.

'Community of practice' describes social mechanisms by which novices are inducted into expert ways of knowing, thinking and reasoning in their professional or practice circle. More specifically, Lave and Wenger (1991) propose that novices' learning involves a process of deepening involvement (legitimate peripheral participation) and greater participation in their community (situated learning). The CoP thus contains a continuum of expertise. In essence, knowledge and cognitive skills of new members are learned through interactions with other new members and more experienced peers; their more experienced peers are in turn learning through 'teaching' novices and through interactions with their colleagues and more experienced peers (i.e., practitioners). Movement along the continuum of expertise is incremental which represents the migration of the limits of the novices' knowledge and skills across 'zones of proximal development' (Vygotsky, 1978).

Functional communities of practice survive through the sharing of experiences, memories, ideas and goals. They also develop various artefacts that reify the foundational and tacit knowledge and experiences of the community. These artefacts may be ephemeral (e.g., emails and documents), behavioural (e.g., oaths), language-based (e.g., vocabulary and jargon), or symbolic (e.g., robes of membership). Some represent the foundation knowledge of the community that can be handed to and shared with others. Other, more tacit aspects of communities such as culture and behaviours, also help them to survive, but can usually only been seen, accessed or acquired through participation in the community.

Social interaction, social construction of knowledge and collaboration underpin learning the knowledge and ways of a profession. Exposure of novices to complexity, multiple ways of accomplishing a task, and interaction with experts and peers, helps learners to recognise that there is no one embodiment of expertise and encourages them to view learning as a continuing process (Vygotsky, 1978) embedded in a social milieu. The premise that knowledge and cognitive skills are best learned if they are embedded in the social and physical contexts in which they must be used (Brown et al., 1989; Norman \& Schmidt, 1992) forms the philosophical basis for the use of case studies in teaching, and problem-based learning (PBL) curricula.

\section{Thinking about problems in the professions}

Education for the professions is based upon the assumption that new practitioners need foundation knowledge and skills before they are competent to practice. Undergraduate medical and nursing students are typically introduced to their professional discipline through a combination of experiences and exploration of the underpinning scientific theory and techniques developed through empirical research. Since the 1900s, the underlying educational philosophy of teaching, for those learning in the professions, has come from a positivist/objectivist viewpoint-an approach which considers knowledge as empirically based and where learners are the recipients of knowledge. This might be considered as a 'technical rational' approach (Schön, 1983), which contributes to the development of foundational knowledge, that is later transformed through 
practice in the real world. The introduction of PBL some 30 years ago (Barrows \& Tamblyn, 1980) has been a major curricular innovation which embeds that transformation within the learning and teaching environment.

The difference between reasoning by undergraduate students, recent medical graduates and medical consultants is related to the perception and representation of a problem. The nature of the work environment is secondary, however, to the ability to represent problems, to see the essential issues and how to resolve them.

The distinction reveals itself in this material in the form of a contrast between a focus on specific symptoms and signs, or short links between causes and effects, and the use of structuring principles to systematize the data and relate them to previous knowledge ... analysis, interpretation and organization of the material are completely absent. These learners clearly display the rational use of these skills; many apparently have the knowledge base ... What appears to be missing in the attempts of the students ... is competence in representing the problem appropriately, so that its inherent structure is maintained. (Ramsden et al., pp. 113-114)

Technical, theoretical or foundational knowledge gained through undergraduate study is transformed through practice. The complexity of knowledge, organisation of knowledge and diagnostic skill changes as novices become expert practitioners (Chang et al., 1998). Working with many real, complex cases in medical settings/contexts shapes the differences in knowledge between novices and experts (Grant \& Marsden, 1988; Schmidt \& Boshuizen, 1993). Professional thinking:

...includes the ability to represent knowledge from different conceptual and case perspectives and then, when the knowledge must later be used, the ability to construct from those different conceptual and case representations a knowledge ensemble tailored to the needs of the understanding or problemsolving situation at hand. (Spiro et al., 1991, p. 24)

The clinical reasoning of medical experts, in their own domain area of expertise, is based upon data derived from a patient case, establishing meaningful relationships among the data and generating out of that case a diagnosis (Groen \& Patel, 1988; Elstein \& Schwartz, 2000). This process involves the ability to sort effectively between relevant and non-relevant information in a case (Patel \& Groen, 1991), and retrieval from a well-structured database of diagnostic representations (Groen \& Patel, 1985). This database of diagnostic representations is developed in part through a process of reasoning on action (Schön, 1983), i.e., reviewing cases and actively accommodating and reconciling their features within their existing knowledge base. Expertise is personal-it depends on past experience of cases, as well as awareness of bias and fallibility. Experience is a prerequisite for expertise.

Experienced practitioners do not always operate on a 'technical rational' or logical basis-there is another dimension to their practice. Polyani (1983) and Schön (1983) describe non-conscious elements of expert performance that cannot be accounted for or verbalised. Experienced practitioners respond to a sense of the whole problem rather than rely solely on evidence and objective reasoning in a process of 'reflection-on-action' and 'reflection-in-action' (Schön, 1983). This process of 'reflection-in-action' might be equivalent to intuition, depending on how Schön's description involving 'appreciation' is considered:

Through stages of appreciation, action and re-appreciation. The unique and uncertain situation becomes understood through both the attempt to change it and [the] change through an attempt to understand it. (Schön, 1983, p. 8) 
Through 'refection-in-action', a problem is reframed and reworked resulting in a newly structured problem. The iterative 'loop' process of reframing and reworking is almost like a deliberative internal conversation involving the practitioner's judgments about the current situation, the repertoire of cases previously experienced and available evidence. Intuition plays a role in many clinical decision-making processes, particularly in cases where there is considerable uncertainty (Benner et al., 1992; Hall, 2002). Intuition and tacit knowledge appear inextricably linked with expert practice.

\section{Learning in an online PBL environment}

PBL uses complex, real-life problems, embedded within a broader scenario, to stimulate learning and motivate students to engage critically with the scenario to come to a meaningful understanding of the foundational elements of the problem. The problem is often prototypical of the types of experiences faced by professionals in the discipline area every day. Students work collaboratively on analysing the problem, consult resources and peers, visit workplaces and engage with practitioners in the process of understanding the problem (Duch et al., 2001). The overall process, normally extending over a week of face-to-face tutorials, is facilitated by a practitionerpeer who operates to assist students in comprehending the broader context of the scenario, as well as raising their metacognitive awareness (Barrows, 1988). Information and communication technologies (ICTs) revolutionised PBL by replacing elements of the face-to-face tutorials with technology-mediated functions within a shared, online learning environment where students and tutors may be geographically separated. This distributed PBL (dPBL) model has many permutations and combinations (Barrows, 2002; Savin-Baden \& Wilkie, 2006) with all students and tutor separated, or small groups of students in separate locations. The ICTs, email, video conferencing, discussion forums etc., may be embedded within a learning management system or custom built within an integrated environment such as WebCaseStudy.com (Zimitat \& Stockhausen, 2002). Overall, PBL and dPBL approximate a CoP operating across university learning and professional workplace environments.

The design principles for WebCaseStudy were synthesised from notions of cognitive apprenticeship and situated learning (Lave \& Wenger, 1991), authentic learning (Oliver, 2000) and cognitive flexibility theory (Spiro et al., 1988) (Table 1). One of the intentions behind the design of WebCaseStudy was to simulate learning processes within CoPs to help students make the transition from undergraduate student to graduate and novice practitioner in the health professions. The professional world is characterised by messy, ill-formed problems encountered in an environment where there are multiple viewpoints, many stakeholders, time pressures, considerable ambiguity and changing priorities (Zsambok \& Klein, 1997). These real world issues were enabled within WebCaseStudy through flexible case design and selection of specific question types (e.g., loop questions) which allowed exploration of ambiguity and inconsistency.

\section{Capturing CoP knowledge}

The CoP of interest consisted of midwives, independent midwives and obstetricians involved in the care of pregnant women and delivery of their newborn. Practice knowledge was elaborated through a knowledge elicitation process (McGraw \& Seale, 1988) involving journal analysis, a 
Table 1. Principles guiding design of the case study software

\begin{tabular}{|c|c|}
\hline Principle & Presence in software \\
\hline \multirow{4}{*}{$\begin{array}{l}\text { Personal construction of } \\
\text { meaning }\end{array}$} & Questions to assist development of personal thinking and reasoning skills \\
\hline & $\begin{array}{l}\text { Design of loop, comparative multiple choice and poll questions encourages learn- } \\
\text { ers to make sense of information, reflect and extend their learning }\end{array}$ \\
\hline & Variety of resources at different levels to support learners \\
\hline & The discussion forum enables learners to articulate and elaborate knowledge \\
\hline \multirow[t]{5}{*}{ Learner support } & Notepad facility for personal note taking \\
\hline & Breadcrumb trail as a navigation support \\
\hline & Help button-context senstitive \\
\hline & Discussion forum and email \\
\hline & Range of teaching modes supported—face to face, blended, online only \\
\hline \multirow[t]{3}{*}{ Multiple learning designs } & Design of cases with presentation of information, supporting data and resources \\
\hline & Flexible sequencing of information and questions \\
\hline & $\begin{array}{l}\text { Use in lecture, tutorial and self-paced modes, use in face-to-face and distance } \\
\text { modes }\end{array}$ \\
\hline \multirow{3}{*}{$\begin{array}{l}\text { Authenticity, complexity } \\
\text { and context }\end{array}$} & Ability to incorporate multimedia to enrich cases \\
\hline & Nature of question formats-short answer, loop, poll etc. \\
\hline & Case development process supports authenticity and complexity \\
\hline \multirow[t]{5}{*}{ Multiple representations } & Presentation of a suite of cases around similar problems \\
\hline & Each case has three challenge/extension cases \\
\hline & $\begin{array}{l}\text { Case structure can be varied to allow development of different schema/knowledge } \\
\text { mapping }\end{array}$ \\
\hline & $\begin{array}{l}\text { Design of loop, comparative multiple choice and poll questions afford presentation } \\
\text { of information from various viewpoints or disciplines }\end{array}$ \\
\hline & Presentation of variety of resources to support learning \\
\hline \multirow{3}{*}{$\begin{array}{l}\text { Multiple perspectives and } \\
\text { community }\end{array}$} & Case design process elicits views from multiple stakeholders, practitioners \\
\hline & Nature of loop and poll questions \\
\hline & Discussion forum links students, tutors, practitioners, experts \\
\hline \multirow[t]{4}{*}{ Scholarly inquiry } & Database design where all student entered data is captured for review and analysis \\
\hline & $\begin{array}{l}\text { Tools available for presentation of interaction statistics (e.g., login time and dura- } \\
\text { tion, case access sequences, access of resources) }\end{array}$ \\
\hline & Tools available for analysis of discussion forum contributions \\
\hline & $\begin{array}{l}\text { Case structure design also allows opportunity for students to reflect on the perfor- } \\
\text { mance and learning through the case study }\end{array}$ \\
\hline
\end{tabular}

series of informal interviews with local midwives, and identification of artefacts related to practice (e.g., documentation, 'rules of thumb', tools). We found that independent midwives had more scope for autonomous activity than hospital staff who were bound by institutional policies and this affected the way each approached their clients. It was also clear that there was a tendency toward specialisation within midwifery (e.g., antenatal care or post-natal care) and so expert midwives were not necessarily involved in the full range of midwifery practices. Discussions with these midwives were not focused on the once-in-a-lifetime case, they covered the common challenges that they faced with their clients. From all of these discussions, we were able to identify typical admissions patterns for clients, their normal progression through the hospital 
system, appropriate artefacts and resources related to admissions (e.g., domestic violence screening forms) and the framework of the cases appropriate for a Masters course. The first case chosen for development was that of a normal pregnancy, with a client living in difficult social circumstances.

The early interviews with midwives revealed a tendency to think in terms of differential diagnoses, rather than providing us with any articulation of their thinking, reflection, elaboration of their experiences or tacit knowledge. In light of this experience, we decided upon a semi-structured approach working through a skeleton case scenario in a sequential manner to simulate a midwife-client interview, with a series of questions included with each part of the unfolding case. These questions were designed to elicit and unpack reasoning behind comments. Is this a realistic/common presentation/problem? What are your thoughts about this situation? Why? What other experiences do you have that relate to that? What are the implications for practice? After discussion of the cases, the expert practitioners were asked about the key messages associated with the case. Experts did explain their rules of thumb used in daily practice and talked about their experiences with tricky clients. These included ways in which to probe the client to distinguish between genuine and non-genuine social issues (e.g., lack of money for transport versus disinterest), and how to conduct phone interviews to distinguish between different symptoms which may or may not be of significance (e.g., pain from intercourse versus Braxton Hicks contractions) and other good practice tips (e.g., never hang up on a client in a phone interview unless you are completely sure they are safe). Whilst considerable tacit knowledge was uncovered, it was not easily applied or relevant to the case under discussion. Indeed, there was much less useable tacit knowledge than we expected.

Each skeleton case, informed by literature, was elaborated through a process involving further interviews with four hospital midwives, an independent midwife and an obstetrician. The skeleton case was presented piece by piece to the expert, interspersed with questions (like those in the previous paragraph) to generate a rich tapestry of experience, practice and context. A range of views from different perspectives, and work contexts were gathered-not all were identical or consistent (Table 2). The basic case framework and data from the interviews were synthesised into a 'typical' scenario with learning affordances (or cues) that were appropriate to the Masters course.

\section{Evaluation of student learning}

The first case study, 'Angie', was one of several prototypical cases built into the teaching program of the Master of Midwifery course to facilitate learning and application of knowledge

Table 2. Four different points of view from different members of the community relating to management of the client who missed an appointment

I would try to contact Angie- by telephone, letter or next of kin

I would try to contact Angie by phone, letter, GP, next of kin, youth services etc. and document all attempts to do so
I would make every effort to try to contact Angie given possible adverse outcomes. Ultimately she has responsibility and we can't follow-up every non-attender ... Do I have a duty of care?

I'd try and contact her by whatever means possible. If I was an independent midwife I'd go and see her. Consider calling the nearest community midwife clinic to see if anyone can visit? 
to the practice situations. Angie was trialled in a tutorial situation where students were asked to work in pairs or individually. The whole tutorial session was observed by teaching staff who took close notice of how students used the program, and how they interacted with each other and the software. All student interactions and brief post-case evaluation questions were recorded within the WebCaseStudy environment.

The students, all of whom were nurses and some of whom were experienced, practising midwives (without the Masters qualification) commented on the 'realness' of the case. Several students had already encountered the scenario in practice, and others thought it was fairly typical of their local community.

\footnotetext{
S6: We see about half a dozen cases like this each week ... pregnant women seeing a doctor for the first time at 34 or 36 weeks!

S7: Yes typical for demographic area of especially here ... many uneducated, poor socio-economic environment. However, not all patients fall into this above category.
}

\section{Interactions among peers and software}

The students working individually were mainly focused on the case. Individuals sitting near to each other frequently discussed issues about the case with their nearby colleagues. They also appeared to welcome the opportunity to discuss the case with staff at different points within the program. Some students' discussions were overheard and their conversation recorded by the observer/s:

S1: Do I have to change my answer?

S2: Not unless you think its necessary.

S1: I looked at the options and I'm not changing my response because it was similar to the expert opinions, so I'm not going to change it.

S3: Why would you give her iron at 36 weeks? It can't make any difference by then.

S4: Giving her a glucose tolerance test at 34 weeks would be a bit tough...

Students working in pairs were very involved with each other and the case study. Both students were active participants in discussions about the content and nature of the expert opinions and comparing them with their own answers. There was much more intense and prolonged discussion amongst these pairs than between individuals sitting close to each other. The pairs looked at each response from WebCaseStudy (e.g., model answer, expert opinions or poll graph) and discussed each in turn. We observed that revised answers were usually co-constructed or coedited. The consensus view amongst students was that for the purposes of a tutorial situation, working in pairs facilitated greatest discussion and engagement with the case study, but they would prefer to revise the case study alone.

\section{Student learning outcomes}

Students were asked about their experience using the case in general discussion and in the postcase evaluation. Two students made comments that they were surprised (at their own behaviour) in prejudging the client in the case study, assuming she was a stereotypical pregnant teenager from a low socio-economic region. They recognised that she could have just transferred to the area, that the admissions clerk passed on information that was misinterpreted (i.e., first time 
Table 3. Improvements in student responses after interaction with peer opinions

\begin{tabular}{|c|c|}
\hline Original & $\begin{array}{l}\text { Explain to Angie that this may be Braxton Hicks contractions, but tell her to come in if it continues } \\
\text { or if she is worried. Find out if there is any bleeding? Explain to her true labour and false labour. } \\
\text { Explain how to time contractions. Tell Angie that it's great that she called. }\end{array}$ \\
\hline Revised & $\begin{array}{l}\text { Explain to Angie that this may be Braxton Hicks contractions, but tell her to come in if it continues } \\
\text { or if she is worried. Find out if there is any bleeding? Explain to her true labour and false labour. } \\
\text { Explain how to time contractions. Tell Angie that it's great that she called. Ask if there were any pre- } \\
\text { cipitating factors such as domestic violence or sex. Tell her to come in and get checked, send ambulance free } \\
\text { of charge. }\end{array}$ \\
\hline
\end{tabular}

presentation cf. first time presentation at this hospital), or that she may have been well informed and comfortable with the pregnancy rather than being poor, in denial or subject to domestic violence. Three experienced midwives made comments that they were also surprised 'that I learnt something' and that that 'most of the time I thought I was right, though there were other avenues that I could have taken'. One said that she was 'frustrated, as it was difficult to decide on the most appropriate type of care as all my clinical experience has been based on policies and procedures, and this has involved a lot of clinical thinking'. The students were surprised how challenging working with a client with a 'routine' pregnancy could be, and considered it an eyeopening introduction to what lay ahead in practice.

The loop question in WebCaseStudy was designed to simulate peer interactions within a CoP and stimulate critical thinking. This question required a student answer, then revealed four peer answers from expert practitioners, after which the student was able to revise their original answer (Table 3). In most instances the revisions were important additions for sake of completeness, or were additions of uncovered tacit knowledge, e.g., using orange juice to increase iron absorption, ensuring complete safety of the client before ending a phone interview, and matters of diagnostic importance. Students were clearly engaging with the peer perspectives, which was designed to simulate learning in a 'zone of proximal development' to scaffold learning and foster critical thinking.

\section{Community}

The pattern of interactions amongst students approximated 'legitimate peripheral participation'. The less-experienced students tended to consult each other first, before asking the more experienced, already practising midwives about the case study. In turn the midwives tended to consult each other first before asking the lecturer. The case study design and learning environment both modelled and facilitated learning as if in a CoP. It appeared to induct students into 'ways of knowing' held by members of the midwifery community.

\section{Final comments}

The case elaboration (or knowledge elicitation) process worked well in providing a detailed scenario set in a realistic context for case studies. The interview process with expert practitioners provided much more information than could be used in one case study. The process here was detailed and not sustainable for development of a larger curriculum without a budget, though it 
is rigorous and would be suitable for generating quality cases for postgraduate courses. However, the use of digital recorders and email would make the process more effective. Furthermore, it would be more useful to map all of the information gained through the interviews against a bank of possible cases, rather than just focus on one case. Indeed, cognitive flexibility theory suggests the need for multiple cases to facilitate learning and transfer across contexts.

The interview process uncovered a broad knowledge base, but little 'inside knowledge', intuition or tacit knowledge related to this case was elicited in this process. To some extent this might have been mitigated by the semi-structured approach to gathering information. Alternatively, there may not have been enough time or triggers for the practitioner to reflect on experience and bring tacit knowledge into consciousness. It may be that greater ambiguity is needed in the case to bring heuristics and intuition to the fore (Hall, 2002). Thus, case studies for WebCaseStudy may need to be crafted from more complex cases in which we are able to capture such tacit knowledge through interview. In future, it would be useful to use a group discussion/focus-group approach to see if this encourages interaction amongst expert practitioners. Indeed, it may also be a useful professional development exercise because an expert's heuristics and intuition are personal, but also subject to biases that can affect decision making. One further source of case development material may be the use of student-generated cases that can be built upon and incorporated in curriculum renewal.

Finally, the case study was successful in its achievement of student learning. The WebCaseStudy software and case study design were able to simulate legitimate peripheral participation, and learning within a zone of proximal development that was situated within a professional practice environment. The utilisation of the discussion forum and other features of WebCaseStudy would likely further enhance the simulation of $\mathrm{CoP}$ and warrants further investigation of its full potential and effectiveness.

\section{Notes on contributor}

Craig Zimitat is Deputy Director (Learning and Teaching Development) at the Centre for Advancement of Learning and Teaching at the University of Tasmania in Australia. He provides academic leadership for eLearning, academic professional development, and institutional research in support of policy development and innovation. Other interests lie in the use of educational technologies to support student learning, internationalisation and all dimensions of the first-year experience.

\section{References}

Barrows, H. S. (1988) The tutorial process (Springfield, Southern Illinois School of Medicine).

Barrows, H. S. (2002) Is it truly possible to have such a thing as dPBL?, Distance Education, 23, 119-122.

Barrows, H. S. \& Tamblyn, R. (1980) Problem based learning. An approach to medical education (New York, Springer Publishing).

Benner, P., Tanner, C. \& Chesla, C. (1992) From beginner to expert. Gaining a differentiated clinical world in critical care nursing, Advances in Nursing Science, 14, 13-28.

Brown, J. S., Collins, A. \& Duguid, P. (1989) Situated cognition and the culture of learning, Educational Researcher, 18, 32-43.

Brown, J. S. \& Duguid, P. (2000) The social life of information (Cambridge, MA, Harvard University Press). 
Chang, R. W., Bordage, G. \& Connell, K. J. (1998) The importance of early problem representation during case presentations, Academic Medicine, 73(10 Suppl.), 109-111.

Duch, B. J., Groh, S. E. \& Allen, D. E. (2001) The power of problem based learning (Stirling, VA, Stylus).

Elstein, A. S. \& Schwartz, A. (2000) Clinical reasoning in medicine, in: J. Higgs \& M. A. Jones (Eds) Clinical reasoning in the health professions (Oxford, Butterworth Heinemann), 95-106.

Eraut, M. (2000) Non-formal learning and tacit knowledge in professional work, British fournal of Educational Psychology, 70, 113-136.

Ericsson, K. A. \& Smith, J. (1991) Toward a general theory of expertise: prospects and limits (New York, Cambridge University Press).

Grant, J. \& Marsden, P. (1988) Primary knowledge, medical education and consultant expertise, Medical Education, 22(3), 173-179.

Groen, G. J. \& Patel, V. L. (1985) Medical problem solving. Some questionable assumptions, Medical Education, 19, 95-100.

Groen, G. J. \& Patel, V. L. (1988) The relationship between comprehension and reasoning in medical expertise, in: M. Chi, R. Glaser \& M. J. Farr (Eds) The nature of expertise (Hillsdale, NJ, Lawrence Erlbaum), 287-310.

Hall, K. H. (2002) Reviewing intuitive decision-making and uncertainty: the implications for medical education, Medical Education, 36, 216-224.

Jonassen, D. H. (1997) Instructional design models of well-structured and ill-structured problem-solving learning outcomes, Educational Technology Research E Development, 45, 65-94.

Lave, J. \& Wenger, E. (1991) Situated learning: legitimate peripheral participation (Cambridge, Cambridge University Press).

McGraw, K. L. \& Seale, M. R. (1988) Knowledge elicitation with multiple experts: considerations and techniques, Artificial Intelligence Review, 2, 31-44.

Norman, G. R. \& Schmidt, H. G. (1992) The psychological basis of problem-based learning: a review of the evidence, Academic Medicine, 67, 557-565.

Oliver, R. (2000) When teaching meets learning. Design principles and strategies for web-based learning environments that support knowledge construction, paper presented at the ASCILITE Conference, Perth, WA, 9-14 December.

Patel, V. L. \& Groen, G. J. (1991) The general and specific nature of medical expertise: a critical look, in: K. A. Ericcson \& J. Smith (Eds) Toward a general theory of expertise. Prospects and limits (New York, Cambridge University Press), 93-125.

Polyani, M. (1983) The tacit dimension (Gloucester, Peter Smith).

Ramsden, P., Whelan, G. \& Cooper, D. (1989) Some phenomena of medical students' diagnostic problem solving, Medical Education, 23, 108-117.

Savin-Baden, M. \& Wilkie, K. (2006) Problem-based learning online (London, Open University Press).

Schmidt, H. G. \& Boshuizen, H. P. A. (1993) On acquiring expertise in medicine, Educational Psychology Review, 5, 205-221.

Schön, D. A. (1983) The reflective practitioner: how professionals think in action (London, Temple Smith).

Spiro, R. J., Coulson, R. L., Feltovich, P. J. \& Anderson, D. K. (1988) Cognitive flexibility theory: advanced knowledge acquisition in ill-structured domain, in: The Tenth Annual Conference of the Cognitive Science Society (Hillsdale, NJ, Lawrence Erlbaum Associates), 375-383.

Spiro, R. J., Feltovich, P. J., Jacobsen, M. J. \& Coulson, R. L. (1991) Knowledge representation, content specification and the development of skill in situation-specific knowledge assembly: some constructivist issues as they relate to cognitive flexibility theory and hypertext, Educational Technology, 31, 22-25.

Vygotsky, L. S. (1978) Mind in society: the development of higher psychological processes (M. Cole, V. John-Steiner, S. Scribner \& E. Souberman, Eds and Trans.) (Cambridge, MA, Harvard University Press).

Williams, R. (1992) Putting case based instruction into context. Examples from legal and medical education, fournal of the Learning Sciences, 2, 367-427.

Zimitat, C. \& Stockhausen, L. (2002) New learning: re-apprenticing the learner, Electronic Media International, $39,332-338$.

Zsambok, C. E. \& Klein, G. (1997) Naturalistic decision making. Expertise research and applications (Mahwah, NJ, Lawrence Erlbaum Associates). 